\title{
Model-based energy path analysis of tip-in maneuvers in a 2WD vehicle with range-extender electric powertrain architec- ture
}

\author{
Raja Mazuir Raja Ahsan Shah ${ }^{1,2 *}$, R. Peter Jones ${ }^{3}$, Caizhen Chen $^{4}$, Alessandro Picarelli ${ }^{5}$, Abd Rashid Abd \\ Aziz $^{6}$, Mansour Al Qubeissi ${ }^{1,2}$ \\ 1 School of Mechanical, Aerospace and Automotive, Coventry University, Coventry, CV1 2JH, United King- \\ dom; e-mail@e-mail.com \\ 2 Research Institute for Clean Growth and Future Mobility, Coventry University, Coventry CV1 5FB, United \\ Kingdom \\ 3 School of Engineering, Warwick University, Coventry, CV4 7AL, United Kingdom \\ 4 Great Wall Motors, Shanghai, China \\ 5 Claytex Services Limited, Leamington Spa, CV32 6EL, United Kingdom \\ 6 Universiti Teknologi Petronas, Seri Iskandar, 32610, Malaysia \\ * Correspondence: mazuirra@yahoo.co.uk, R.M.R.A.S
}

\begin{abstract}
Vehicle driveability is one of the important vehicle attributes in range-extender electric vehicles due to the electric motor torque characteristics at low-speed events. The process of validating and rectifying vehicle driveability attributes is typically utilised by a physical vehicle prototype that can be expensive and required several design iterations. In this paper, a model-based energy method to assess vehicle driveability is presented based on a high-fidelity 49 degree-of-freedom powertrain and vehicle systems. Multibody dynamics components were built according to their true centre of gravity relative to the vehicle datum for providing an accurate system interaction. The work covered a frequency at less than $20 \mathrm{~Hz}$. The results that consisted of the component frequency domination are structured and examined to identify the low-frequency sensitivity based on different operating parameters such as a road surface coefficient. An energy path technique was also implemented on the dominant component by decoupling its compliances to study the effect on the vehicle driveability and low-frequency response. The outcomes of the research provided a good understanding of the interaction across the sub-systems levels. The powertrain rubber mounts were the dominant components that controlled the low-frequency contents $(<15.33 \mathrm{~Hz})$ and can change the vehicle driveability quality.
\end{abstract}

Keywords: Driveability; low-frequency; energy path analysis; powertrain; model-based engineering

\section{Introduction}

According to the International Energy Agency [1], the global volume of electric vehicles (EVs) in 2030 is forecasted to reach 245 million, an increase from 7.2 million in 2019. The market demand for the type of EV varies based on several factors such as the vehicle's range and price. One of the EV architectures that can increase the vehicle range is a rangeextender electric vehicle (REEV). A report by Grand View Research [2] estimated the REEVs will have a market growth of $100 \%$ in 2026 compared to 2018 . The concept of REEV uses an electric motor (EM) for the sole propulsion of the vehicle, and range-extenders (REx) such as internal combustion (IC) engine or microturbine generator to charge the battery energy storage (BES) or to provide the electrical energy to the EM through power electronics hardware [3].

One of the issues with REEVs is the higher vehicle mass due to the REx and BES that will affect the vehicle dynamics characteristics [4]. Milliken and Milliken [5] established 
four important criteria that influence the driver perception such as ride, handling, performance, and driveability. The ride attribute refers to the vertical responses of the vehicle when driven on different road surface coefficients ( $\mathrm{mu}$ [6]. The handling attribute relates to the lateral responses due to the transverse wheel motion to the direction of the vehicle such as lane change and cornering [7]. The refinement of handling quality and ride comfort is a continuous process through the vehicle development stage to determine the optimum vehicle set-up between these vehicle attributes. For instance, Liu et al. [8] established this process using the dynamics kinematics and compliance rigs, suspension dynamometer testing, and other testing equipment. On the other hand, the vehicle performance attribute describes the powertrain (PT) capability to meet specific loads at anticipated speeds. It uses the gear ratios strategies [9] and the shift quality [10] to achieve the vehicle system targets and has less dependency on the ride and handling attributes. In terms of vehicle driveability, which is the main focus of this work, Shah et al. [11] indicated that the driveability attribute reflects the vehicle longitudinal responses to torque demand in the form of throttle pedal excitation under specific driving conditions.

According to Dorey and Holmes [12], vehicle driveability typically focuses on vehicle low-speed events such as acceleration/deceleration, one of the important factors for continuous product decision making and has demanding characteristics at the vehicle system level. Previously, the process of vehicle driveability assessment used a prototype vehicle. and at a later stage of the vehicle development process that can be challenging to rectify any design issue. To meet the future REEVs market demands and challenges, advanced simulation tools have been used to study vehicle driveability in the early stage of the vehicle development process as performed by Wang et al. [13]. The implementation of a model-based method in REEVs highlights the complex nonlinear system interaction under torque demand and identifies the factors associated with vehicle driveability concerns. For instance, Ciceo et al. [14] used the model-based method to design and validate the control strategy of the electric PT system to improve vehicle driveability. The model-based method in REEVs can also study the low-frequency response below $20 \mathrm{~Hz}$ that influences the vehicle driveability behaviour [15]. Previous studies showed that the arrangement of IC engine mounts can influence vehicle driveability [16] and the low-frequency response [17]. A previous study by Shah et al. [18] also highlighted the vehicle shuffle frequency migration due to the throttle responses at low-speed events due to the torque amplification. The vehicle frequency responses are expected to be similar in REEVs due to the high EM torque at the low-speed region [19]. From the literature, the high EM torque excitation at vehicle low-speed event manifests the complex interaction between the sub-system components such as the driveline system [20,21] and the 6-degree-of-freedom (DoF) rubber mounts [22] that dominates the vehicle's low shuffle frequency response. Similar to ride comfort, the irregularities of road surfaces can also influence the low-frequency response. For instance, Ivanoz et al. [23] investigated the torque compensation for the driveline system on a polished ice road to improve the vehicle driveability. Also, a splitmu road surface has the same influence on the driveline response as found in the literature $[24,25]$.

The model-based method can study the energy flow from a throttle pedal input to a vehicle body, and define the transfer function that controls the vehicle longitudinal response. A transfer path analysis (TPA) technique can be used to study the energy flow between system components, the low-frequency response, and determine the dominant components that control the system response [26]. Most of the TPA studies on vehicle systems were focused on high-frequency vibration as discussed in [27-30]. In terms of driveability, Jimbo et al. [31] used an experimental TPA technique to analyse the behaviour of the vehicle during acceleration. The TPA technique also allowed for a couple-decouple process of the compliances to identify the shuffle frequency domination and to determine the tuning parameters for the driveability refinement [16]. Zhang et al. [32] also used the couple-decouple method to identify the dominant mode for a ride and handling characteristics of the 7-DoF vehicle systems based on suspension system elements. 
This paper is to present the model-based method for vehicle driveability study of REEV model at low-speed events using energy path analysis (EPA) technique derived from the TPA technique. It consists of two objectives 1) simulation on different road mu and identify the dominant component for the low-frequency response and 2) decouplingcoupling of the dominant component and its properties to investigate the influence on vehicle driveability and low-frequency response.

\section{System model and methodology for vehicle driveability study}

\subsection{REEV model architecture}

The study was based on a previous study performed by Shah et al. [33] using an IC engine propulsion four-wheel-drive (4WD) vehicle architecture. The 4WD vehicle model was correlated with a full nonlinear ADAMS vehicle model and vehicle test data. In this study, the vehicle architecture was replaced with a two-wheel-drive (2WD) vehicle architecture by removing the rear drivetrain system and the IC engine propulsion system. The concept of REEV uses EM as the sole propulsion of the vehicle and an IC engine as the REx to charge the BES or provide the electrical energy to the propulsion system through power electronics hardware as shown in Figure 1. Other subsystem arrangements remained the same as 4WD vehicle architecture.

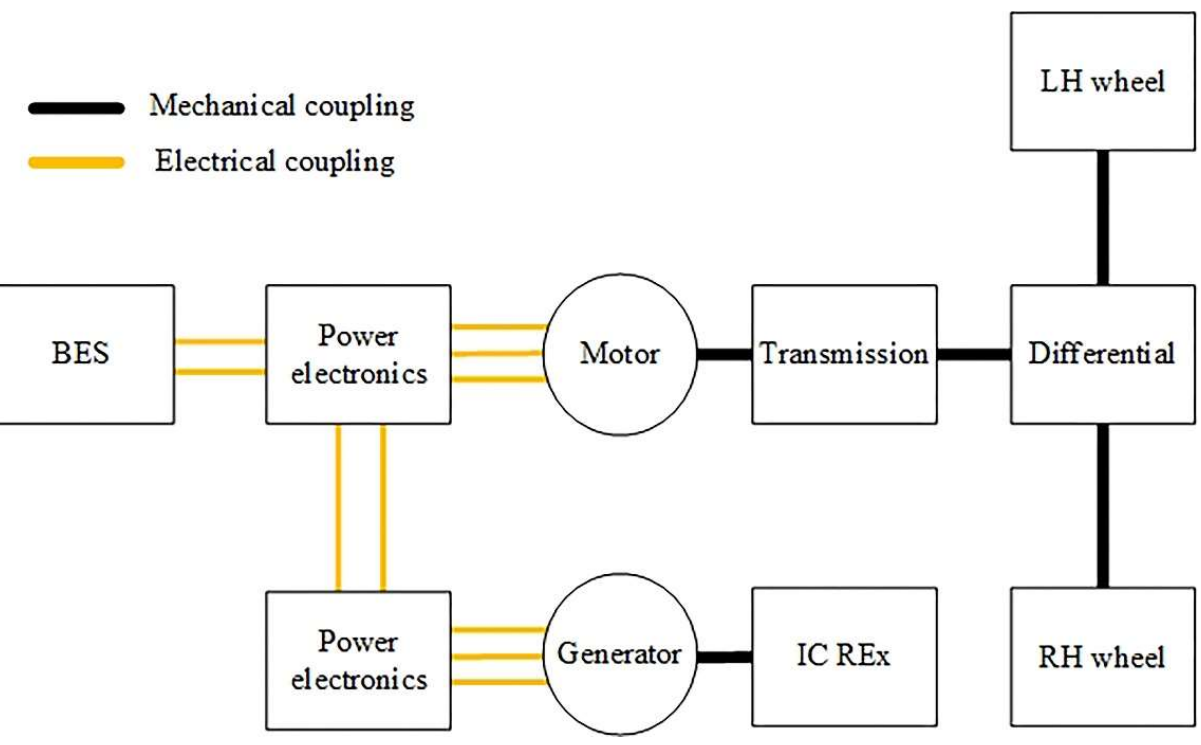

Figure 1. The basic architecture of REEV with an electric motor, generator, IC engine REx, BES, and power electronics.

Figure 2 shows the block diagram of the high fidelity 49-DoF REEV model with linear and nonlinear compliances connected between the components. All PT (EM and REx) components were mounted on a structural PT cradle and to the vehicle structural components using a right-hand (RH) rubber mount, a left-hand (LH) rubber mount, a front rollstopper, and a rear roll-stopper. The DoF of rubber mounts was reduced to three, namely longitudinal, yaw, and pitch directions that have significant effects on the low-frequency response [34]. Other linear and nonlinear compliances were fixed in the longitudinal direction that dominated the vehicle driveability response. 


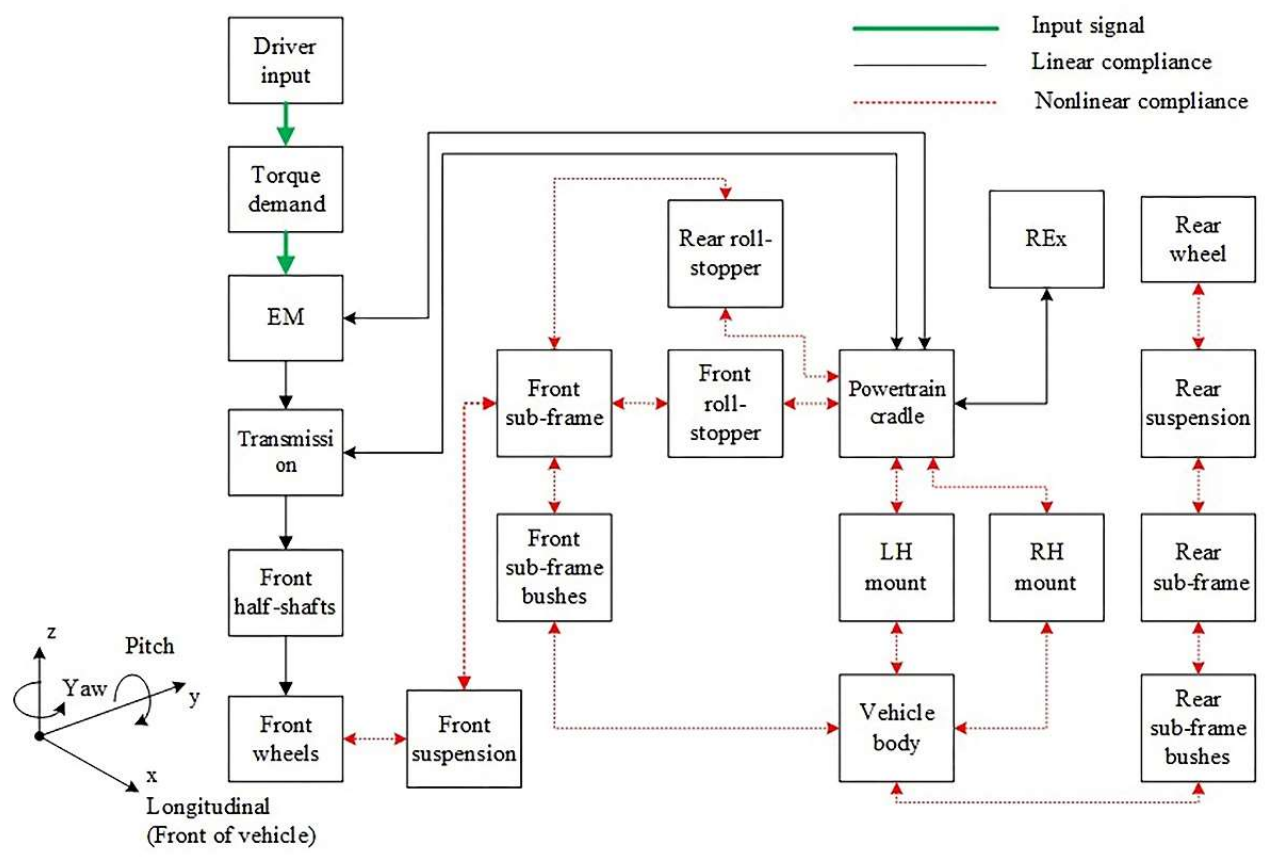

Figure 2. Block diagram of 2WD REEV system architecture interaction.

A REEV high-fidelity model was constructed based on Figure 2 using a multibody dynamic library in DYMOLA, a multiphysics modelling tool. The RH rubber mount and the LH rubber mount consisted of longitudinal nonlinear stiffness properties, yaw, and pitch linear stiffness properties as shown in Figure 3(a). Both RH and LH rubber mounts were connected to the front subframe and vehicle body. The PT cradle pitch was controlled by the front and rear roll-stoppers and consisted of a nonlinear rubber bush, rig rod, and linear rubber bush as shown in Figure 3(b). The nonlinear rubber bush and the linear rubber bush were connected to the PT cradle and the front subframe respectively. The nonlinear stiffness properties and the linear properties of PT rubber mounts and rollstopper rubber bushes are shown in Table 1 and Figure 3 (c).

Table 1. Linear stiffness and damping properties of PT cradle rubber mounts and roll-stopper rubber bushes

\begin{tabular}{cccc}
\hline Components & Properties & Values & Units \\
\hline \multirow{3}{*}{ RH rubber mount } & Damping & 190 & $\mathrm{~N} \cdot \mathrm{s} / \mathrm{m}$ \\
& Pitch stiffness & $1.528 \times 10^{-2}$ & $\mathrm{~N} \cdot \mathrm{m} /{ }^{\circ}$ \\
& Yaw stiffness & $3.898 \times 10^{-1}$ & $\mathrm{~N} \cdot \mathrm{s} / \mathrm{m}$ \\
\hline \multirow{3}{*}{ LH rubber mount } & Damping & 100 & $\mathrm{~N} \cdot \mathrm{s} / \mathrm{m}$ \\
& Pitch stiffness & $1.528 \times 10^{-2}$ & $\mathrm{~N} \cdot \mathrm{m} /{ }^{\circ}$ \\
& Yaw stiffness & $3.898 \times 10^{-1}$ & $\mathrm{~N} \cdot \mathrm{m} /{ }^{\circ}$ \\
\hline \multirow{2}{*}{ Front roll-stopper rubber bush } & Stiffness & $1 \times 10^{8}$ & $\mathrm{~N} / \mathrm{m}$ \\
& Damping & 60 & $\mathrm{~N} \cdot \mathrm{s} / \mathrm{m}$ \\
\hline \multirow{2}{*}{ Rear roll-stopper rubber bush } & Stiffness & $1 \times 10^{8}$ & $\mathrm{~N} / \mathrm{m}$ \\
& Damping & 130 & $\mathrm{~N} \cdot \mathrm{s} / \mathrm{m}$ \\
\hline
\end{tabular}




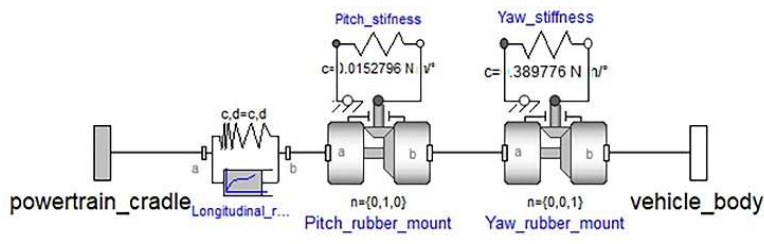

(a)

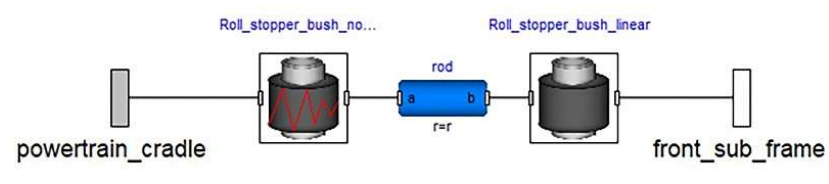

(b)

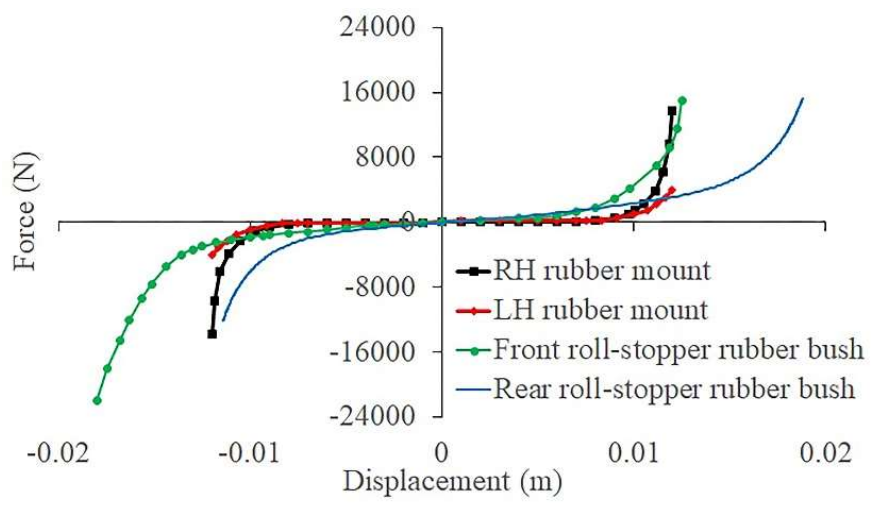

(c)

Figure 3. PT cradle mounting models: (a) 3-DOF RH and LH rubber mounts; b) longitudinal front and rear roll-stopper rubber bushes and rigid rod; c) longitudinal nonlinear stiffness properties.

Figure 4(a) shows the model of the front subframe and rear subframe that has the same bushes arrangement. The front subframe was connected to the vehicle body using four bushes; bush_1 - 2 at the top-end position and bush_3 - 4 at the low-end position. Also, the rear subframe was connected to the vehicle body using the same four bushes (bush_1 - 4). In Figure 4(b), the front RH and LH suspensions were connected to the front wheels and the front subframe, and the rear RH and LH suspensions were connected to the rear wheels and the rear subframe. The subframe bushes and the properties of the suspension are shown in Table 2 and Figure 4(c).

Table 2. Linear damping properties of subframe bushes and suspensions.

\begin{tabular}{ccc}
\hline Components & Values & Units \\
\hline Front subframe bush_1-2 & $1.81 \times 10^{3}$ & $\mathrm{~N} \cdot \mathrm{s} / \mathrm{m}$ \\
Front subframe bush_3-4 & $1.01 \times 10^{3}$ & $\mathrm{~N} \cdot \mathrm{s} / \mathrm{m}$ \\
Rear subframe bush_1-4 & $5.5 \times 10^{2}$ & $\mathrm{~N} \cdot \mathrm{s} / \mathrm{m}$ \\
Front RH and LH suspensions & $3.5 \times 10^{2}$ & $\mathrm{~N} \cdot \mathrm{s} / \mathrm{m}$ \\
Rear RH and LH suspensions & $2.5 \times 10^{2}$ & $\mathrm{~N} \cdot \mathrm{s} / \mathrm{m}$ \\
\hline
\end{tabular}




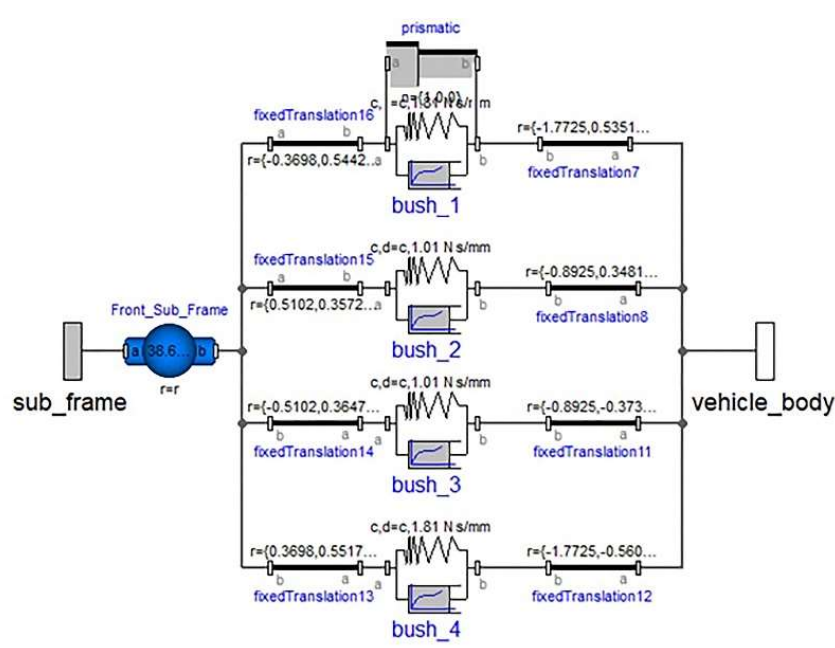

(a)

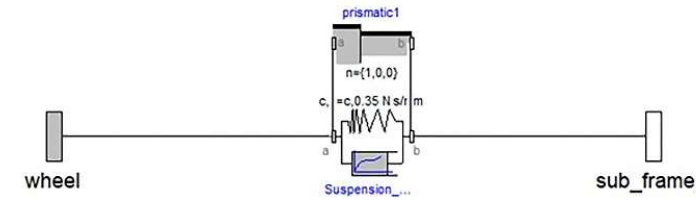

(b)

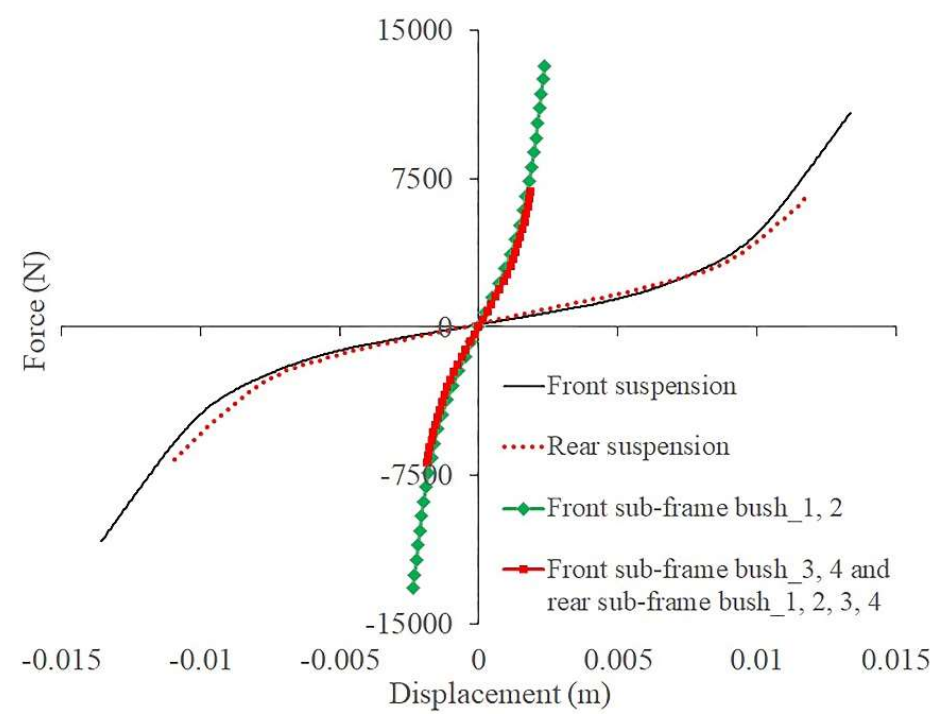

(c)

Figure 4. Longitudinal nonlinear compliance models: (a) front and rear subframe with bushes; b) front and rear suspensions; c) stiffness properties.

Pacejka tyre model was used to excite the REEV model in a longitudinal direction using two inputs, namely wheel slip ratio, and normal load. The wheel slip ratio, $\mathrm{s}_{\mathrm{w}}$ is defined by equation 1 [5], where $V_{a}$ is the actual vehicle speed. The normal load, $F_{z}$ can be calculated based on the dynamic weight transfer acting on the wheel and given by equation 2, where $\mathrm{ax}_{\mathrm{x}}$ is the vehicle longitudinal acceleration, $\mathrm{F}_{\mathrm{z}}{ }^{\prime}$ is the initial normal load, $\mathrm{h}$ is the vehicle body centre of gravity $(\mathrm{CoG})$ relative to the front wheel centre in z-axis direction and 1 is the wheelbase (distance between the front wheel centre and the rear wheel centre in y-axis direction). The tyre model coefficient was parameterised from the experiment data from the tyre supplier. The vehicle parameters are listed in Table 3.

$$
\begin{gathered}
\mathrm{s}_{\mathrm{w}}=\left(\mathrm{rew}_{\mathrm{ew}} / \mathrm{V}_{\mathrm{a}}\right)-1, \\
\mathrm{~F}_{\mathrm{z}}=\mathrm{F}_{\mathrm{z}}{ }^{\prime}+\mathrm{m}_{\mathrm{s}} \mathrm{ax}_{\mathrm{x}}(\mathrm{h} / \mathrm{l}),
\end{gathered}
$$


Table 3. 2WD REEV parameters.

\begin{tabular}{cccc}
\hline Parameters & Symbols & Values & Units \\
\hline Frontal area & $\mathrm{A}$ & 2.5 & $\mathrm{~m}^{2}$ \\
Coefficient of drag & $\mathrm{C}_{\mathrm{d}}$ & 0.3 & \\
Vehicle body (including BES) mass & $\mathrm{m}_{\mathrm{s}}$ & 1670.5 & $\mathrm{~kg}$ \\
PT mass & $\mathrm{m}_{\mathrm{pt}}$ & 251.3 & $\mathrm{~kg}$ \\
Front subframe mass & $\mathrm{m}_{\mathrm{fsf}}$ & 38.7 & $\mathrm{~kg}$ \\
Rear subframe mass & $\mathrm{m}_{\mathrm{rsf}}$ & 15.6 & $\mathrm{~kg}$ \\
Front tyre mass & $\mathrm{m}_{\mathrm{fw}}$ & 41.6 & $\mathrm{~kg}$ \\
Rear tyre mass & $\mathrm{m}_{\mathrm{rw}}$ & 38.2 & $\mathrm{~kg}$ \\
Static weight distribution & & $57: 43$ & \\
Maximum EM torque & $\tau_{\mathrm{em}}$ & 320 & $\mathrm{~N} \cdot \mathrm{m}$ \\
Transmission & & 7.139 & Total ratio \\
Differential type & & $50: 50$ & Open \\
Tyre rolling resistance & $\mathrm{C}_{\mathrm{rr}}$ & 0.018 & \\
Effective tyre rolling radius & $\mathrm{rew}_{\mathrm{ew}}$ & 0.3415 & $\mathrm{~m}$ \\
\hline
\end{tabular}

To simulate the effect of multibody dynamics, all components were built to their actual CoG using Cartesian coordinates about the front $\mathrm{RH}$ wheel coordinate as shown in Table A1.

\subsection{Throttle pedal excitation}

One of the effective methods to excite the vehicle for the driveability study is a tip-in event to obtain the maximum torque excitation from the EM to the half-shaft $[35,36]$. In this study, the initial vehicle speed was set at $40 \mathrm{~km} / \mathrm{h}$ and coasted down to $20 \mathrm{~km} / \mathrm{h}$. Subsequently, $70 \%$ throttle position was applied within 0.12 seconds (s) rate and kept constant until the REEV model reached $40 \mathrm{~km} / \mathrm{h}$. Figure 5 shows the simulation procedures of the tip-in event for the REEV driveability study. Three types of road mu were used on the vehicle driveability analysis, namely tarmac, polished ice, and split-mu as shown in Table 4. From the simulation, the investigation will be concentrated on the interaction between the PT cradle and structural vehicle components, namely the front subframe and rear subframe. The frequency response of each of the compliances will also be investigated.

Table 4. Three road mu values for driveability analysis of REEV.

\begin{tabular}{ccc}
\hline Road surfaces & Right wheels & Left wheels \\
\hline Tarmac & 0.85 & 0.85 \\
Polished ice & 0.10 & 0.10 \\
Split-mu & 0.85 & 0.10 \\
\hline
\end{tabular}




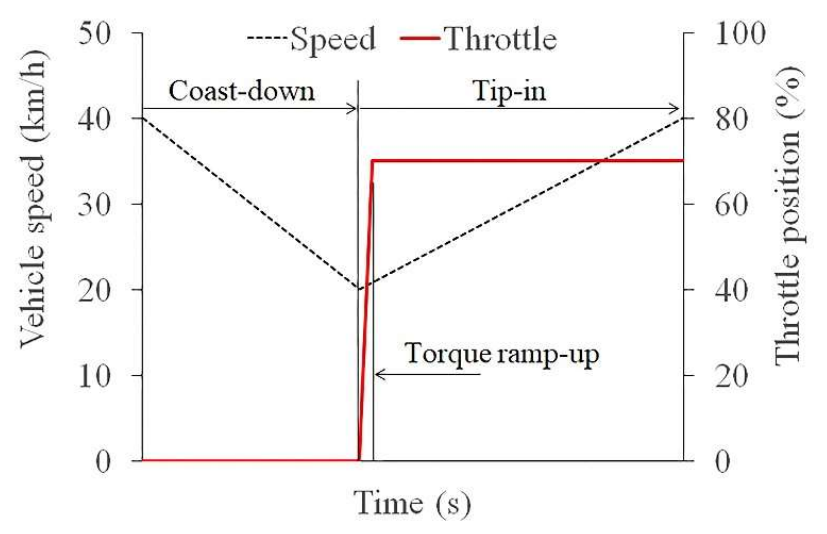

Figure 5. Tip-in test procedures for REEV driveability analysis at 70\% throttle position.

The EM torque required to excite the model can be defined from equation 3.

$$
\tau_{\mathrm{em}}=\left(\mathrm{m}_{\mathrm{t}}\left(\mathrm{ax}+\mathrm{g} \mathrm{C}_{\mathrm{rr}}\right)+0.5 \rho \mathrm{C}_{\mathrm{d}} \mathrm{V}_{\mathrm{a}}^{2}\right) \mathrm{rew}_{\mathrm{e}}
$$

Where $m_{t}$ is the vehicle's total mass, $=m_{s}+m_{f w}+m_{r w}$. The vehicle frequency migration, $\mathrm{f}_{\mathrm{m}}$ is calculated using equation 4 , where $\mathrm{k}_{\mathrm{v}_{-}}$is the vehicle effective stiffness.

$$
\mathrm{f}_{\mathrm{m}}=\sqrt{\mathrm{k}_{\mathrm{v}_{-} \mathrm{e}} / \mathrm{m}_{\mathrm{t}}}
$$

A mode shape analysis was also performed to study the vehicle driveability behaviour of three road mu. The dynamic equations for rotating and multibody dynamic components are given by equation 5 and equation 6 respectively to form a square matrix.

$$
\begin{aligned}
& F_{w}(t)=m_{n} \ddot{x}+B_{n} \dot{x}+C_{n} x, \\
& \tau_{e m}(t)=J_{z} \ddot{\theta}+D_{z} \dot{\theta}+K_{z} \theta
\end{aligned}
$$

$\mathrm{m}, \mathrm{J}, \mathrm{B}, \mathrm{D}, \mathrm{C}$ and $\mathrm{K}$ are the component mass, shaft inertia, compliance damping, shaft damping, compliance spring stiffness and shaft stiffness respectively. $\mathrm{n}$ and $\mathrm{z}$ are the number of mass and rotating components. The REEV model was linearized using the DYMOLA linearization facilities to generate an A matrix to obtain an eigenvector, $\vec{v}$ and an eigenvalue, using equation 7 to identify the dominant components for the low-frequency response on each of the road mu.

$$
\mathrm{A} \overrightarrow{\mathrm{v}}=\lambda \overrightarrow{\mathrm{v}}
$$

\section{Results}

\subsection{REEV model on three road mu}

In Figure 6(a), the vehicle body longitudinal acceleration on the tarmac is higher as the half-shaft can wind up at a faster rate and helped the front wheels to gain better traction compared to polished ice and split-mu. It can be observed that during torque rampup, an acceleration dip occurred on all roads mu particularly on the tarmac. The PT cradle acceleration responses in longitudinal, lateral, and vertical directions are shown in Figure 
6(b), (c), and (d). Similar to the vehicle body longitudinal acceleration, the PT cradle longitudinal acceleration was higher on the tarmac compared to the polished ice and the splitmu.
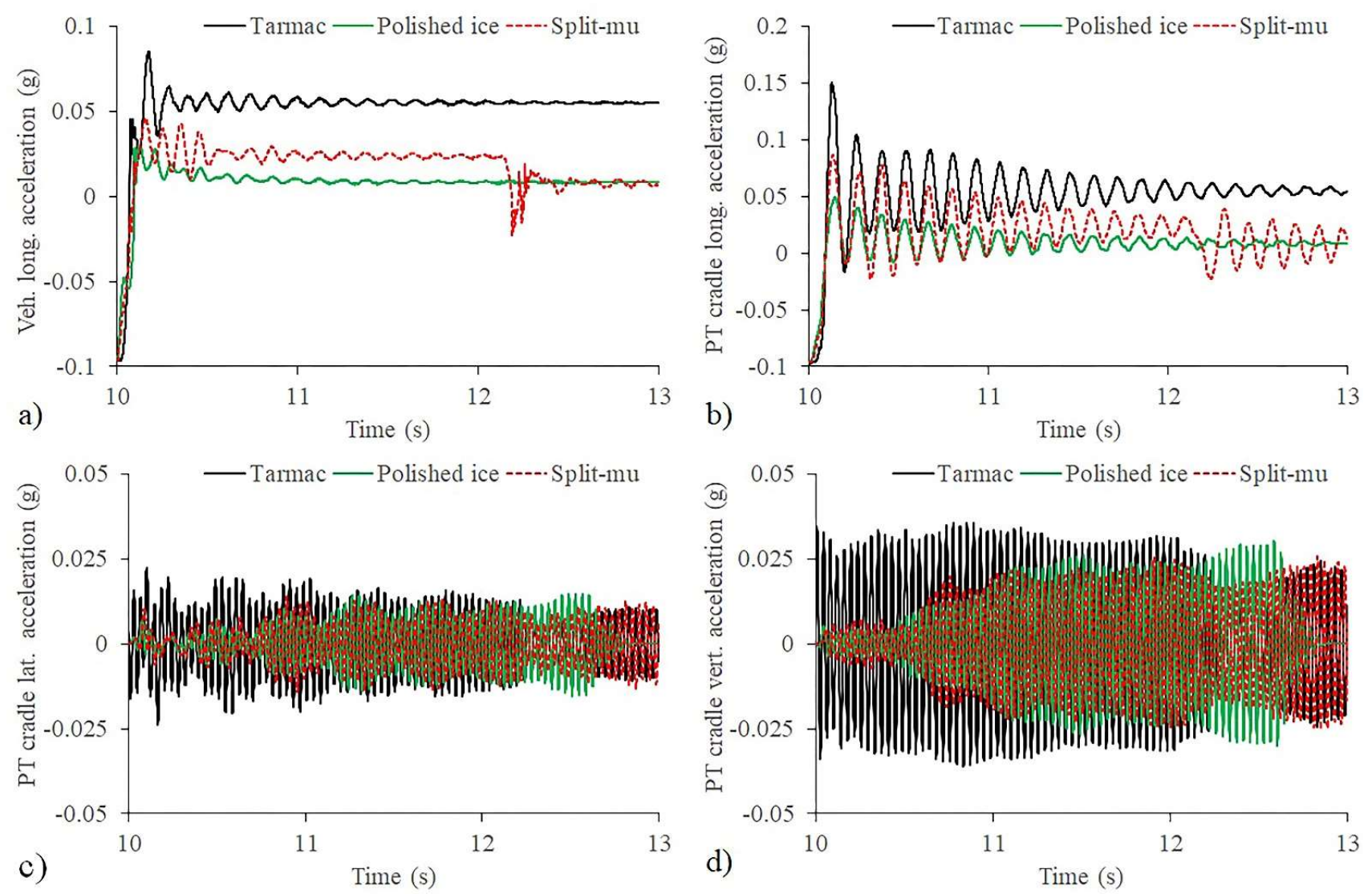

Figure 6. Tip-in event components acceleration on different road mu: a) vehicle body longitudinal; b) PT cradle longitudinal; c) PT cradle lateral; d) PT cradle vertical.

Each of the PT cradle longitudinal acceleration responses generated low-frequency responses of $15.3 \mathrm{~Hz}$ with an additional frequency on the split-mu surface due to the weight surge event as a result of the front RH and the LH wheels interaction (see Figure 7). In terms of the PT cradle lateral acceleration, the values were relatively small compared to the longitudinal acceleration and more responsive on the tarmac. These responses showed that the lateral excitation was adequately controlled by the rubber mount yaw properties. The vertical acceleration was more responsive on all road mu compared to the lateral acceleration due to the fast EM torque excitation. The front and rear roll-stoppers minimized the magnitude of the vertical acceleration to the adequate level that might affect the vehicle ride attribute [37]. 

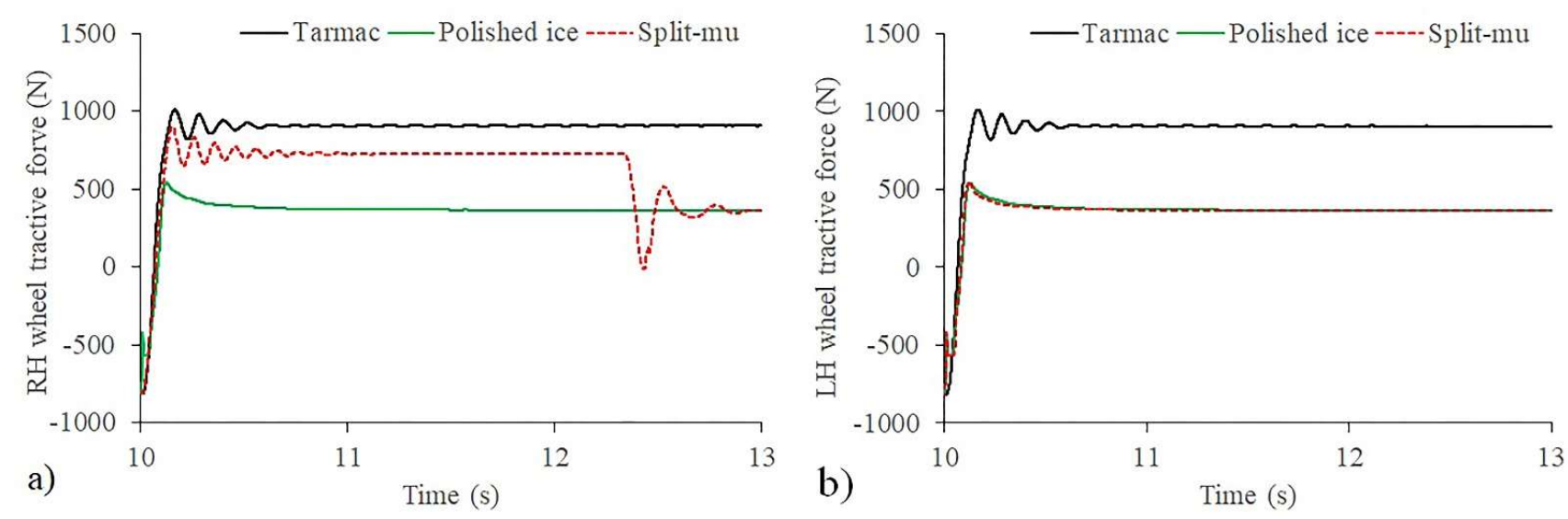

Figure 7. Tip-in event tractive force on different road mu: a) front wheel; b) rear wheel.

The front subframe and the rear subframe longitudinal acceleration responses are shown in Figure 8. On the polished ice, the front wheel and the rear wheel tractive forces were slightly damped by the front subframe bushes. As the EM torque increased, the front subframe bushes properties could not cope with the high force transfer rate; subsequently became rigid and generated a higher amplitude and oscillation. It was suggested that this response caused the acceleration dip during torque ramp-up on the vehicle body and also existed on the tarmac and split-mu. A judder was apparent particularly on the tarmac due to the mechanical coupling where the high-frequency vibration was transmitted to the front subframe through the rear roll-stopper bushes. It can also be observed in Figure 8(b) that the rear subframe nonlinear bushes characterized the vehicle body longitudinal acceleration response. On the tarmac, the rear subframe produced high excitation during torque ramp-up but reduced significantly on the low friction surfaces as the effect of the bushes nonlinearity.
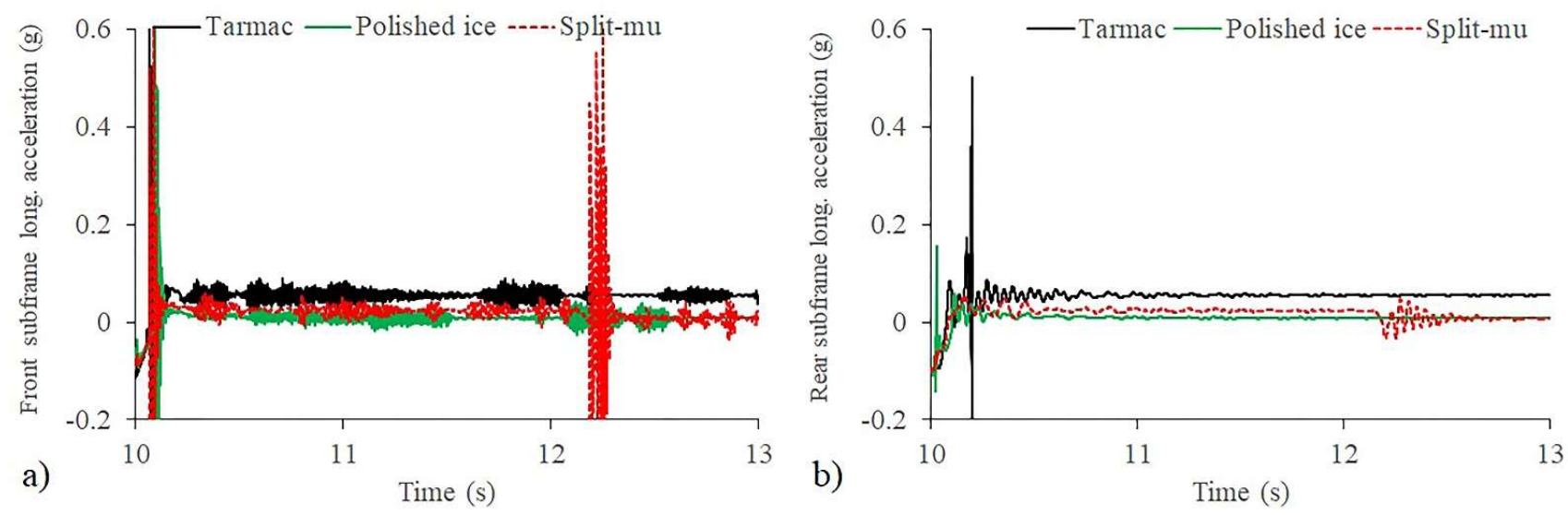

Figure 8. Tip-in event longitudinal acceleration on different road mu: a) front subframe; b) rear subframe.

The fast Fourier transform (FFT) method was used to determine the power spectral density of the vehicle body response and the dominant components as shown in Figure 9. It can be observed that the low-frequency resonant of vehicle body longitudinal acceleration on all road mu was dominantly controlled by the PT cradle and the front wheel longitudinal accelerations. For instance, on the tarmac, the vehicle body longitudinal acceleration produced low-frequency resonant of $15.33 \mathrm{~Hz}$ and $18.66 \mathrm{~Hz}$, which were similar to the PT cradle longitudinal and the front wheel longitudinal 
accelerations low-frequency resonant respectively. In terms of the vehicle body longitudinal acceleration on the polished ice, these low-frequency resonant were only controlled by the PT longitudinal acceleration. As the result of a complex interaction between the front RH wheel and the LH wheel on the split-mu, the vehicle body longitudinal acceleration response produced eight low-frequency resonant; $2.66 \mathrm{~Hz}, 4.66$ $\mathrm{Hz}, 7.33 \mathrm{~Hz}, 10 \mathrm{~Hz}, 12 \mathrm{~Hz}, 14 \mathrm{~Hz}$, and $20 \mathrm{~Hz}$ that was controlled by the front wheel longitudinal acceleration, and $15.33 \mathrm{~Hz}$ that was controlled by the PT cradle longitudinal acceleration.

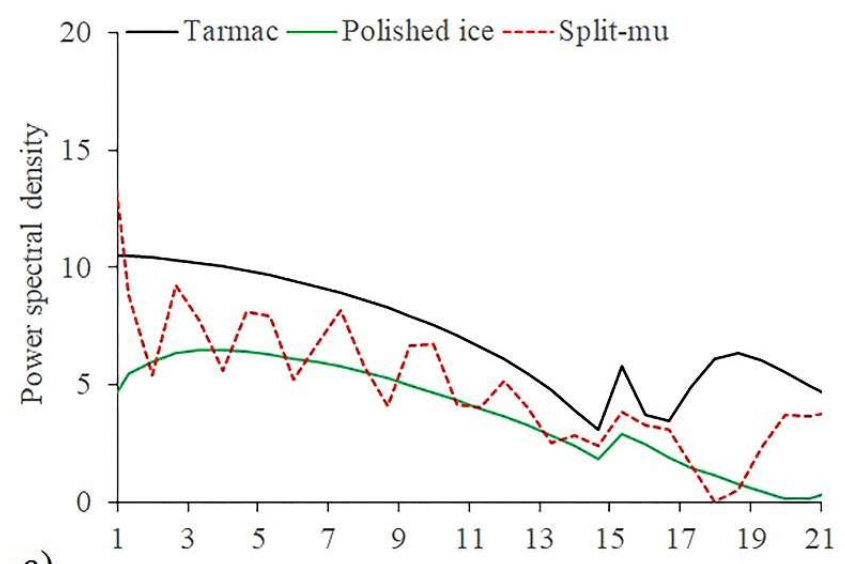

a)

Frequency $(\mathrm{Hz})$

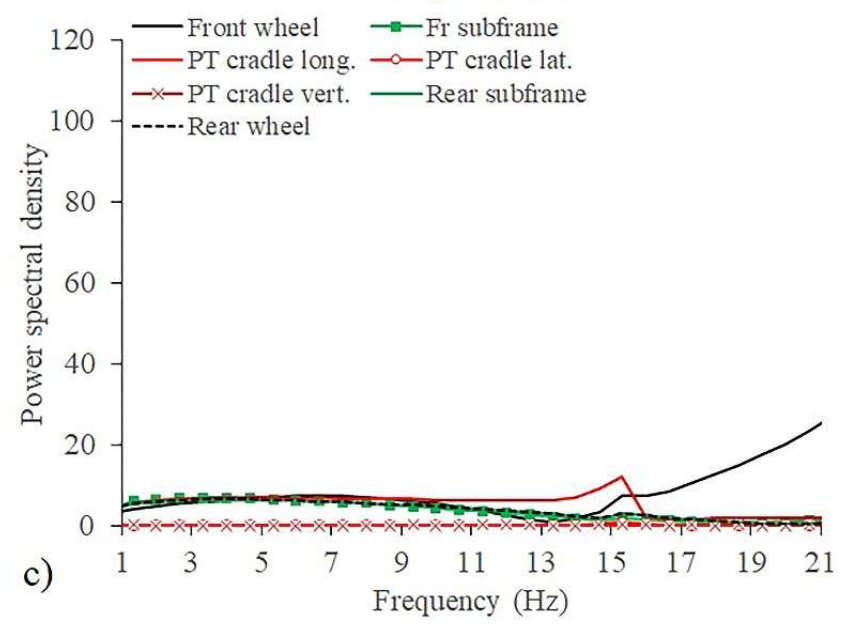

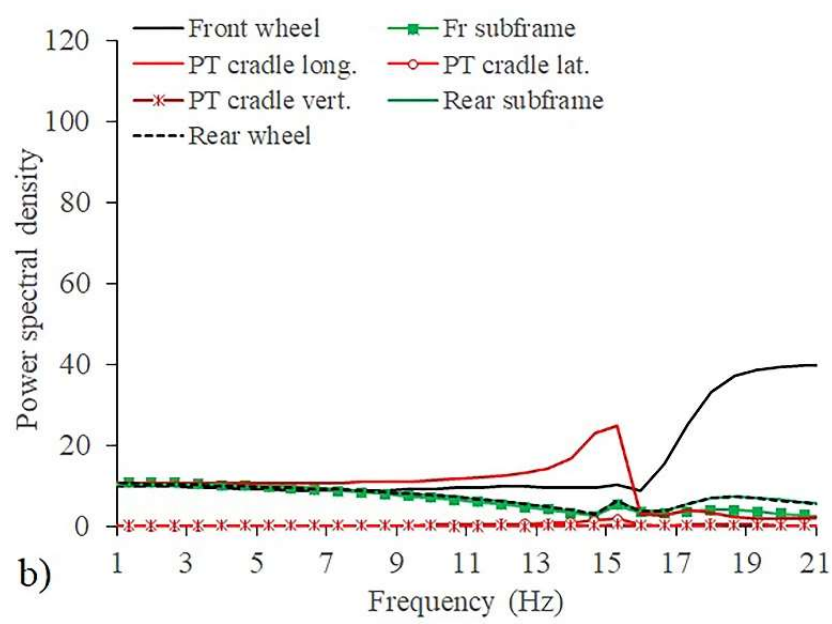

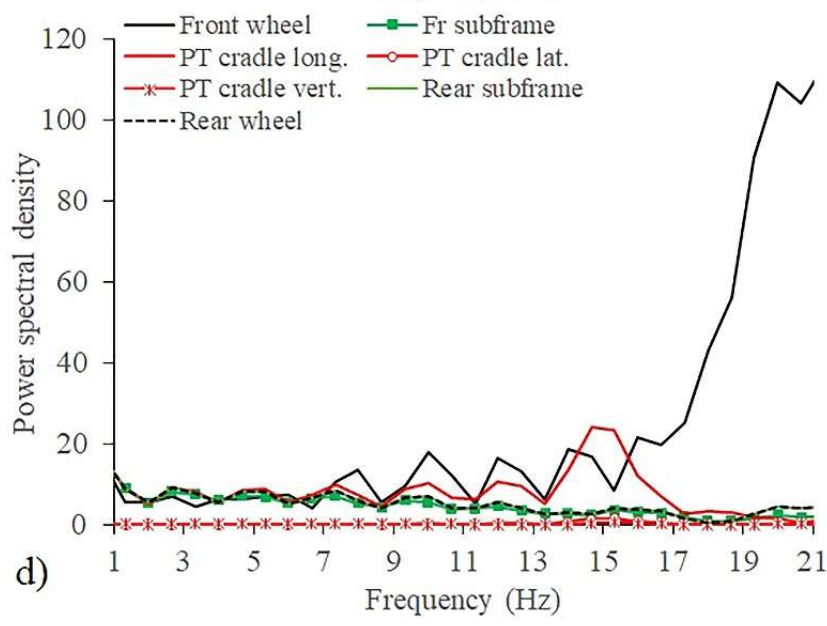

Figure 9. Tip-in event low-frequency resonant of component acceleration: a) vehicle body longitudinal on different road $\mathrm{mu}$; b) dominant component on tarmac; c) dominant components on polished ice; d) dominant components on split-mu. 

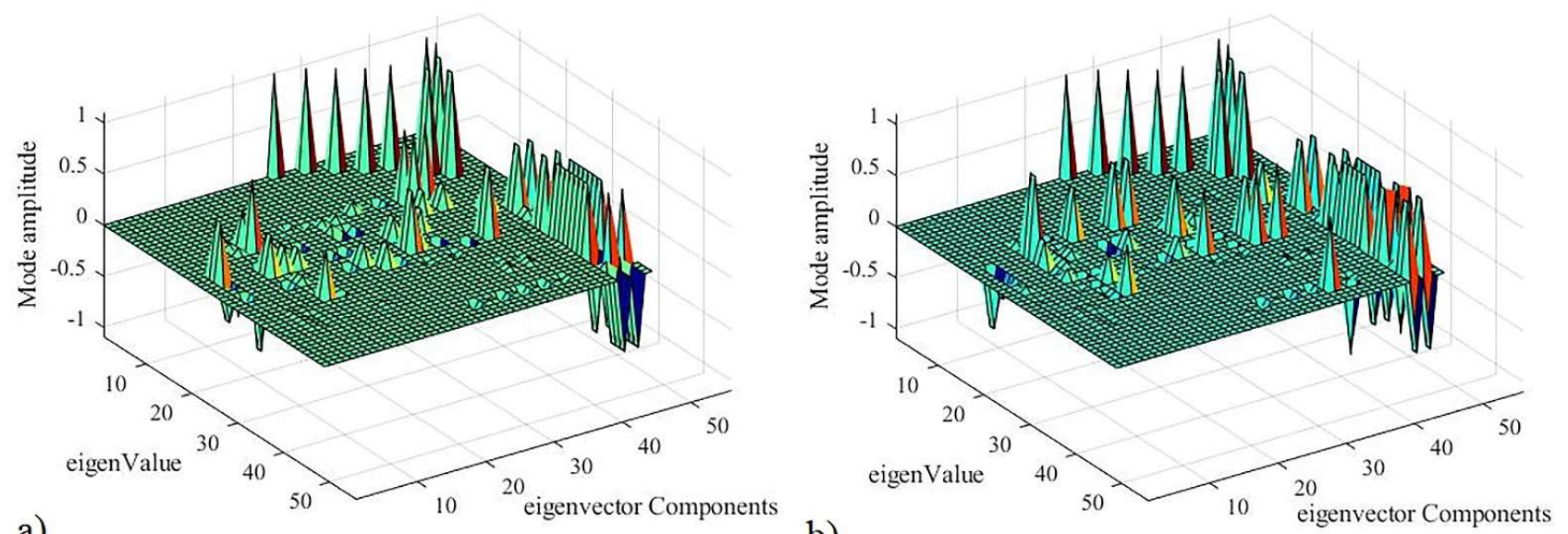

a)

b)

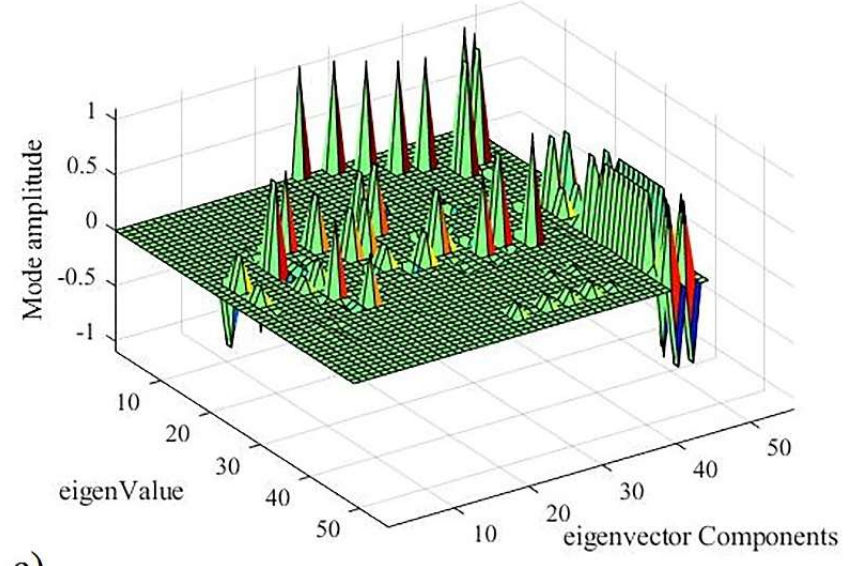

c)

Figure 10. Mode shape analysis of linearized REEV model on; a) tarmac; b) polished ice; c) split-mu..

Using the mode shape analysis method; the eigenvalue, the eigenvectors, and the magnitude were obtained for the linearized REEV model with no EM torque input on different road mu as shown in Figure 10. The linearization of the REEV model produced similar results to the steady-state and transient-state conditions, where the PT cradle longitudinal properties and the front wheel altered the mode shape array and amplitudes on different road mu for every eigenvalue.

\subsection{EPA on decoupled dominant components}

From the analysis on three road mu, it has been identified that the PT cradle has the dominant effect on the vehicle body driveability and low-frequency resonant, which aligns with the literature. The importance of 3-DOF rubber mounts and roll-stoppers concerning the vehicle driveability was investigated further by decoupling their properties from the REEV model on the tarmac and compared to the reference REEV model. To implement the EPA technique, five case studies were investigated as shown in Table 5 with the same tip-in test procedure. 
Table 5. Case studies of PT cradle mounting properties decoupled process.

\begin{tabular}{|c|c|c|c|c|c|}
\hline \multirow{2}{*}{ Case studies } & \multicolumn{3}{|c|}{$\mathrm{RH} / \mathrm{LH}$ rubber mount properties } & \multirow{2}{*}{$\begin{array}{l}\text { Front roll-stop- } \\
\text { per properties } \\
\text { Longitudinal }\end{array}$} & \multirow{2}{*}{$\begin{array}{c}\text { Rear roll-stopper } \\
\text { properties } \\
\text { Longitudinal }\end{array}$} \\
\hline & Longitudinal & Yaw & Pitch & & \\
\hline Case 1 & decoupled & $\checkmark$ & $\checkmark$ & $\checkmark$ & $\checkmark$ \\
\hline Case 2 & $\checkmark$ & decoupled & $\checkmark$ & $\checkmark$ & $\checkmark$ \\
\hline Case 3 & $\checkmark$ & $\checkmark$ & decoupled & $\checkmark$ & $\checkmark$ \\
\hline Case 4 & $\checkmark$ & $\checkmark$ & $\checkmark$ & decoupled & $\checkmark$ \\
\hline Case 5 & $\checkmark$ & $\checkmark$ & $\checkmark$ & $\checkmark$ & decoupled \\
\hline
\end{tabular}

\subsubsection{RH and LH rubber mounts properties (case 1 - 3)}

From Figure 11(a), the RH and LH rubber mount longitudinal properties were significantly characterised the PT cradle longitudinal acceleration response. The amplitude and the damping ratio of PT cradle longitudinal acceleration response were substantially changed and developed a frequency migration. The effect of the rubber mount's yaw and pitch properties on the PT cradle longitudinal acceleration response was minimal and negligible. In terms of the PT cradle lateral and vertical acceleration, the decoupled rubber mounts longitudinal properties also provided similar responses and relatively insignificance as shown in Figure 11(b)-(c).

Through the rest of Figure 11, the decoupled of all rubber mount properties have less influence on the front wheel longitudinal acceleration. This is because the PT cradle was not directly connected to the front wheel, where the force intensity was considerably low and damped by the front wheel and the front suspension. However, without the rubber mount longitudinal properties, the front subframe longitudinal acceleration was more responsive compared to the other two properties. The vehicle body longitudinal acceleration response was altered corresponded to the front subframe and the PT cradle responses by decoupling the rubber mount longitudinal properties. The vehicle body longitudinal acceleration response also required a longer settling time and generated a lower natural frequency. The acceleration dip was still present in all decoupled rubber mount properties cases. The nonlinear rear subframe bushes were affected by the decoupling of rubber mount longitudinal properties compared to the yaw and pitch properties, with higher amplitude and a lower damping ratio. A similar effect on the rear suspension was also observed where it excited the rear wheel with a low damping ratio. 


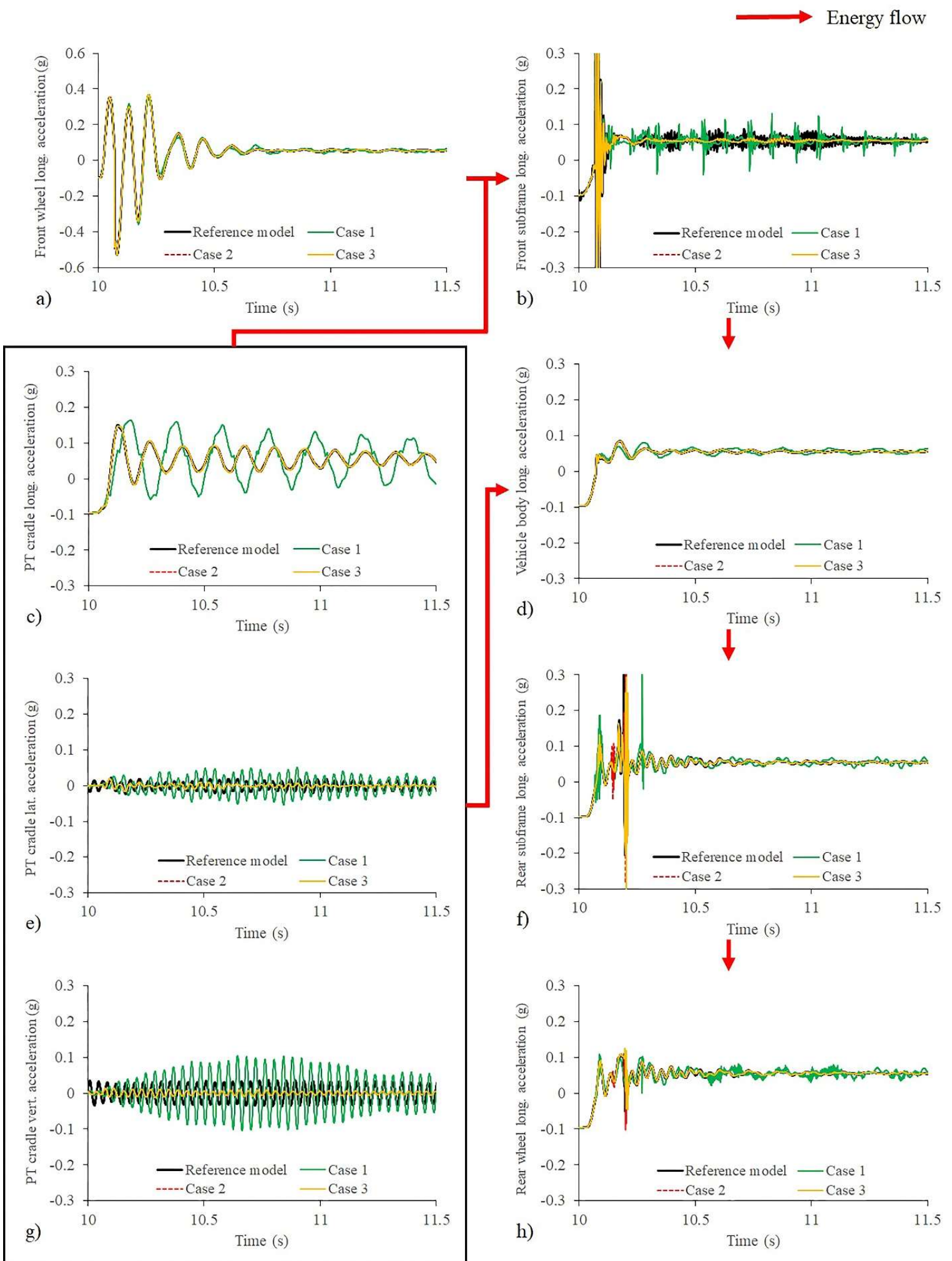

Figure 11. Tip-in event components accelerations EPA on the tarmac and decoupled PT cradle rubber mount properties: a) front wheel longitudinal; b) front subframe longitudinal; c) PT cradle longitudinal; d) vehicle body longitudinal; e) PT cradle lateral; f) rear subframe longitudinal; g) PT cradle vertical; h)PT cradle vertical acceleration; h) rear wheel longitudinal. 
In Figure 12(a), the decoupled rubber mount yaw and pitch properties generated the same vehicle body longitudinal acceleration low-frequency resonant. However, the decoupled rubber mount longitudinal properties migrated the low-frequency resonant from $15.33 \mathrm{~Hz}$ to $10.33 \mathrm{~Hz}$. Figure 12(b)-(c) provide the frequency response sensitivity for each of the dominant components' acceleration magnitude corresponded to the decoupled of rubber mount properties. In all cases, the low-frequency resonant were controlled by the PT cradle longitudinal acceleration and the front wheel longitudinal acceleration dominated the low-frequency resonant above $16.66 \mathrm{~Hz}$
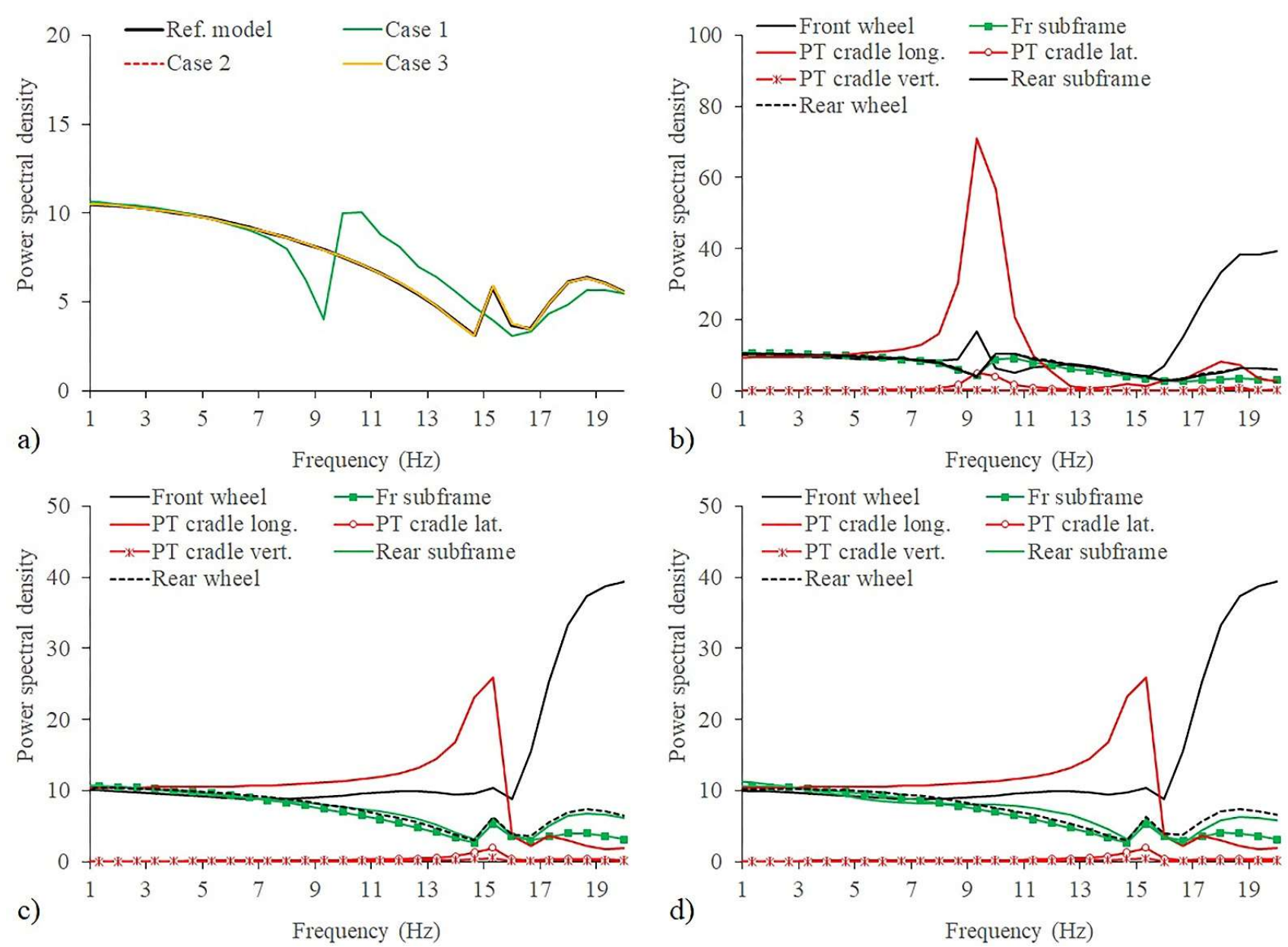

Figure 12. Tip-in event low-frequency responses on the tarmac: a) vehicle body; b) case 1; c) case 2; d) case 3 .

\subsection{Front and rear roll-stoppers (case $4-5$ )}

The components acceleration energy path and the influence of front and rear rollstoppers on vehicle driveability can be observed in Figure 13(a)-(h). The PT cradle was pitched enormously without the rear roll-stopper and changed the acceleration response in all directions and its frequencies. The decoupling of the front roll-stopper also caused an aggressive PT cradle longitudinal acceleration response but has a marginal effect in the lateral and vertical accelerations. The diversity of PT cradle accelerations was due to the different mounting positions of the front and rear roll-stoppers. 

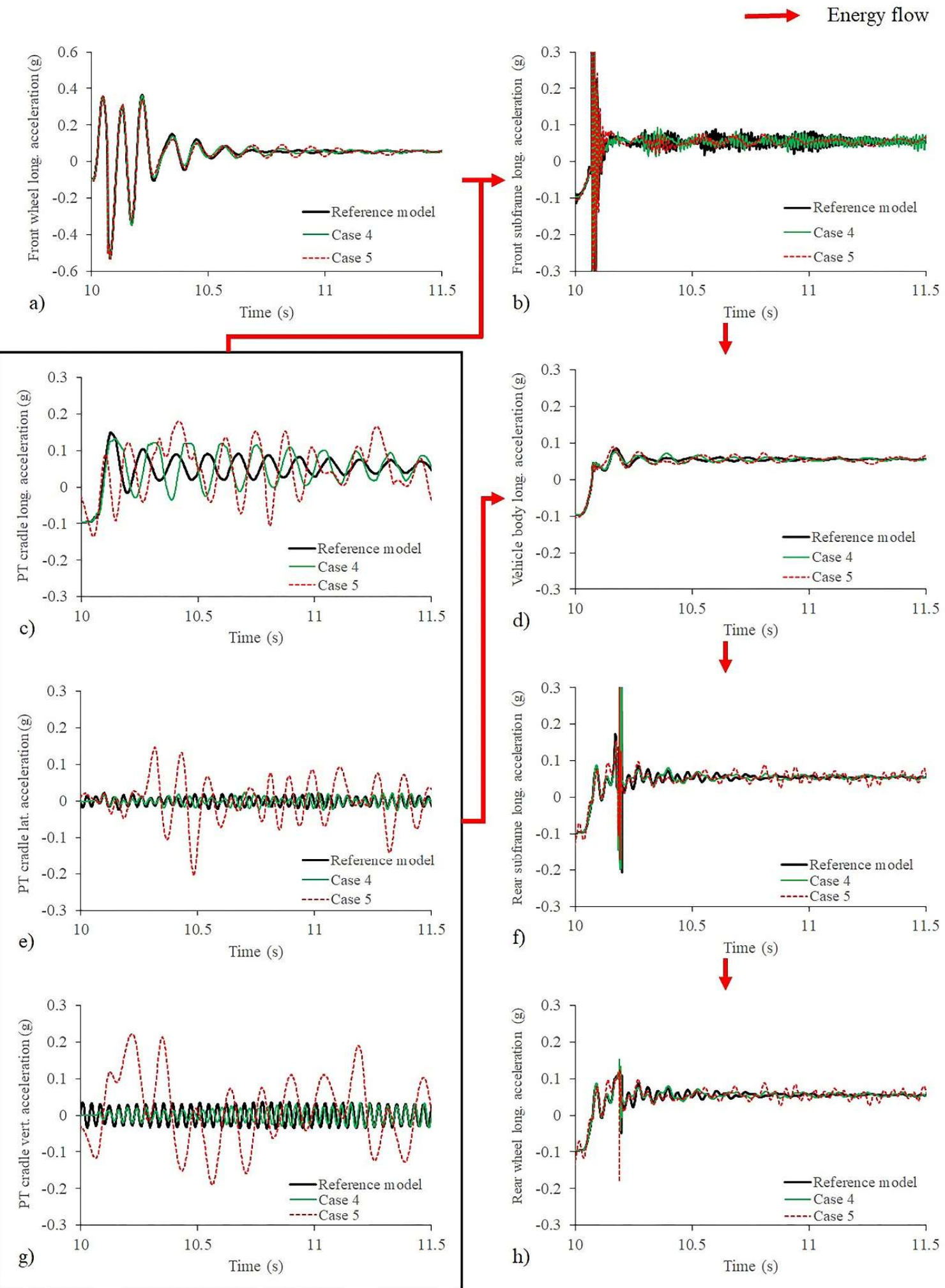

Figure 13. Tip-in event components accelerations EPA on the tarmac and decoupled PT cradle rubber mount properties: a) front wheel longitudinal; b) front subframe longitudinal; c) PT cradle longitudinal; d) vehicle body longitudinal; e) PT cradle lateral; f) rear subframe longitudinal; g) PT cradle vertical; h)PT cradle vertical acceleration; h) rear wheel longitudinal. 
The differences of front wheel longitudinal acceleration for both roll-stoppers were not significant compared to the reference model within 10.6 seconds of the excitation but changed the response subsequently due to the higher force excitation from the PT cradle, which was then transferred to the front subframe. By decoupling the front roll-stopper, the front subframe generated a high frequency during the tip-in event and suggested that the rear roll stopper has a rigid connection between the PT cradle and the front subframe through the nonlinear bushes. The decoupled of both roll-stoppers also caused a phase shift between the vehicle body and the reference model. From the power spectral density analysis in Figure 14(a), the low-frequency resonant vehicle body longitudinal acceleration was migrated from $15.33 \mathrm{~Hz}$ to $13.33 \mathrm{~Hz}$ and dominated by the PT cradle longitudinal acceleration as shown in Figure 14 (b). On the other hand, the decoupled of rear roll-stopper as shown in Figure 14(c), migrated the vehicle body longitudinal acceleration low-frequency resonant from $15.33 \mathrm{~Hz}$ to $5.33 \mathrm{~Hz}, 8.66 \mathrm{~Hz}, 10.66 \mathrm{~Hz}, 12.66$ $\mathrm{Hz}$, and $7.33 \mathrm{~Hz}$ that were dominated by the PT cradle vertical acceleration and PT cradle longitudinal acceleration respectively. Other resonant frequencies were controlled by the front-wheel longitudinal acceleration.
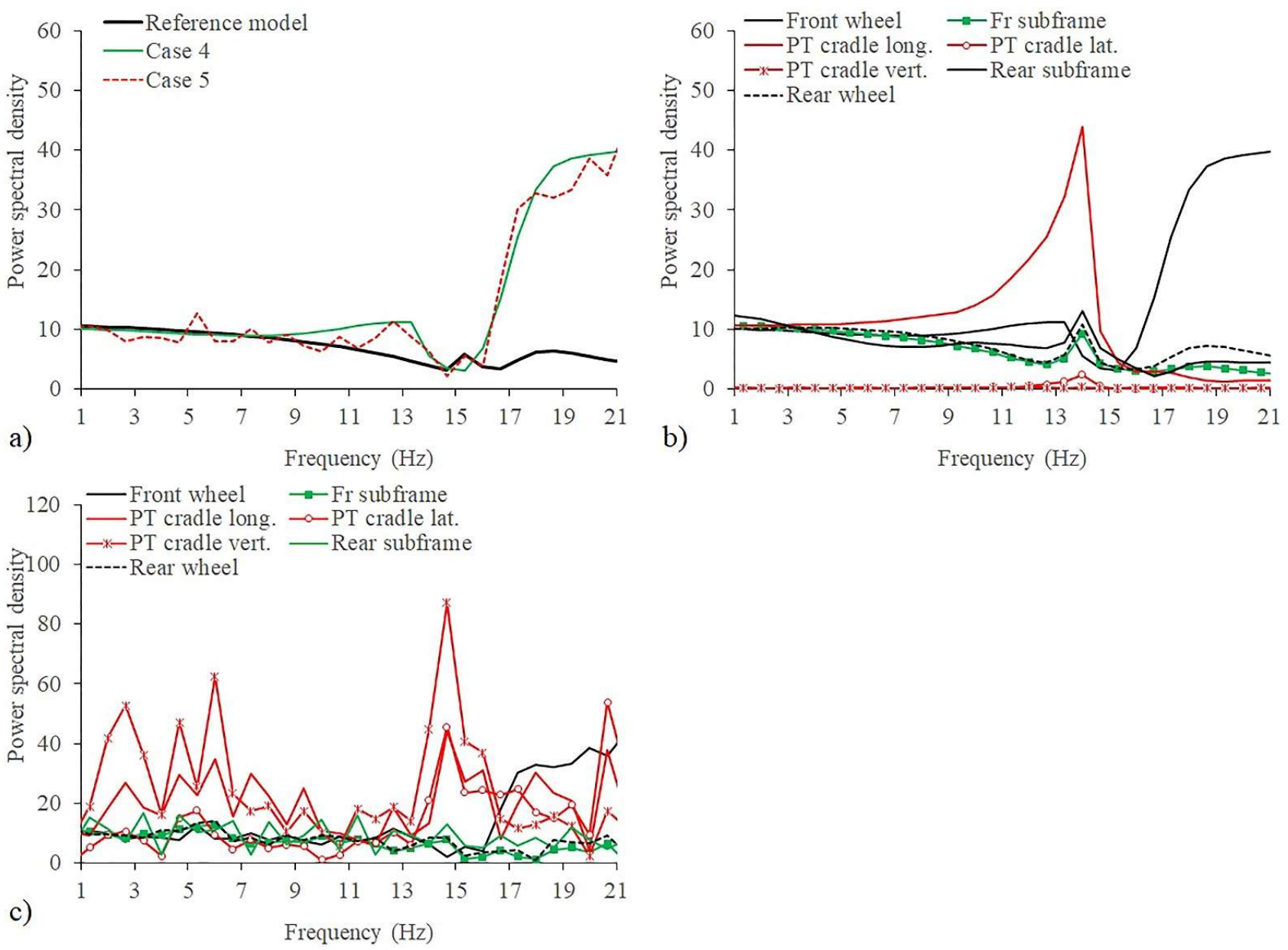

Figure 14. Tip-in event low-frequency responses on the tarmac: a) vehicle body; b) case 4; c) case 5. 


\section{Conclusions}

The model-based EPA technique was a useful tool to determine the responses of dominant components acceleration on the vehicle body acceleration. The mode shape analysis method has provided a good insight into the components and the compliances responses under different road conditions. These parameters can then be tuned for vehicle driveability refinement. Based on the road surfaces simulations, the relationships with the dominant components have been established such as the front wheel and the PT cradle mainly due to its longitudinal response. The level of coupling between the torsional components and the chassis components was sensitive to the low surface coefficient, where it has changed the components' responses. The EPA technique identified the unwanted characteristics of the vehicle acceleration such as the acceleration dip as a result of the interaction within the vehicle system such as the front suspension and the subframe bushes.

The decoupled simulation method was significant to determine the design requirement of the dominant components such as rubber mount, front roll-stopper, and rear rollstopper. These components were significant to characterise the resonant frequency of the front wheel and the PT cradle. The longitudinal and the pitch responses of the PT cradle were seen to have the predominant effect on the vehicle body longitudinal acceleration behaviour either in the time domain or frequency domain, which has been highlighted for detailed attention of the hardware tuning.

Author Contributions: Conceptualization, Raja Mazuir Raja Ahsan Shah; Formal analysis, Raja Mazuir Raja Ahsan Shah; Funding acquisition, Mansour Al Qubeissi; Investigation, Raja Mazuir Raja Ahsan Shah; Methodology, Raja Mazuir Raja Ahsan Shah; Project administration, Raja Mazuir Raja Ahsan Shah; Resources, Raja Mazuir Raja Ahsan Shah; Software, Raja Mazuir Raja Ahsan Shah and Alessandro Picarelli; Validation, Raja Mazuir Raja Ahsan Shah; Visualization, Raja Mazuir Raja Ahsan Shah; Writing - original draft, Raja Mazuir Raja Ahsan Shah and R. Peter Jones; Writing - review \& editing, Raja Mazuir Raja Ahsan Shah, R. Peter Jones, Caizhen Cheng, Alessandro Picarelli, Abd Rashid Abd Aziz and Mansour Al Qubeissi.

Funding: This research was funded by the European Commission, KA107 British Council grant numbers: 2020-1-UK01-KA107-078517.

Acknowledgments: The authors would also like to thank the School of Engineering, the University of Warwick, United Kingdom for their commitments and ideas

Conflicts of Interest: On behalf of all the authors, the corresponding author states that there is no conflict of interest.

\section{Appendix A}

Table A1. Cartesian coordinates of REEV components and compliances in $\mathrm{mm}$.

\begin{tabular}{cccc}
\hline Parameters & $\mathbf{X}$ & $\mathbf{Y}$ & $\mathbf{Z}$ \\
\hline Front RH wheel (datum) & 0.0 & 0.0 & 0.0 \\
Front LH wheel & 0.0 & 1596.0 & 0.0 \\
Vehicle body & 1000.0 & 798.0 & -500.0 \\
Front subframe & 1000.0 & 798.0 & 0.0 \\
Front subframe bush 1 & 630.2 & 253.7 & 222.7 \\
Front subframe bush 2 & 630.2 & 1349.7 & 222.7 \\
Front subframe bush 3 & 1510.2 & 440.7 & -14.3 \\
Front subframe bush 4 & 1510.2 & 1162.7 & -14.3 \\
Powertrain cradle & 877.6 & 766.5 & 255.3 \\
Front roll stopper rod & 853.6 & 287.7 & 661.6 \\
\hline
\end{tabular}




\begin{tabular}{cccc}
\hline Front roll-stopper bush to powertrain cradle & 756.1 & 287.7 & 648.8 \\
Front roll-stopper bush to vehicle body & 950.9 & 287.7 & 674.7 \\
Rear roll stopper rod & 1082.7 & 498.1 & 20.6 \\
Rear roll-stopper bush to powertrain cradle & 1024.2 & 498.1 & 11.7 \\
Rear roll-stopper bush to front subframe & 1141.7 & 498.1 & 29.5 \\
RH rubber mount & 862.2 & 266.2 & 542.2 \\
LH rubber mount & 923.2 & 1259.7 & 470.5 \\
Rear subframe & 2000.0 & 798.0 & -500.0 \\
Rear subframe bush 1 & 1800.0 & 498.0 & -200.0 \\
Rear subframe bush 2 & 1800.0 & 1098.0 & -200.0 \\
Rear subframe bush 3 & 2200.0 & 1098.0 & -200.0 \\
Rear subframe bush 4 & 2200.0 & 498.0 & -200.0 \\
Rear RH wheel & 3000.0 & 1.3 & -500.0 \\
Rear LH wheel & 3000.0 & 1594.7 & -500.0 \\
\hline
\end{tabular}

\section{References}

1. Global EV Outlook 2020, Paris, France, International Energy Agency, 2020.

2. Electric Vehicle Range Extender Market Size, Share \& Trends Analysis Report By Product, By Vehicle (Passenger, Commercial), By Component (Battery Pack, Power Converter), And Segment Forecasts, 2018 - 2025, https://www.grandviewresearch.com/industry-analysis/electric-vehicle-ev-range-extender-market, 2018 (accessed 10 July 2021).

3. R. M. R. A. Shah, A. McGordon, M. M. Rahman, M. Amor-Segan, P. Jennings, Characterisation of micro turbine generator as a range extender using an automotive drive cycle for series hybrid electric vehicle application, Applied Thermal Engineering. 184 (2021) 116302. https://doi.org/10.1016/j.applthermaleng.2020.116302.

4. D. A. Crolla, D. Cao, The impact of hybrid and electric powertrains on vehicle dynamics, control systems and energy regeneration, Vehicle System Dynamics. 50 (2012) 95-109. https://doi.org/10.1080/00423114.2012.676651.

5. W. F. Milliken, D. L. Millike, Race Car Vehicle Dynamic, Warrendale, Society of Automotive Engineers, 1995.

6. G. Loprencipe, P. Zoccali, Ride Quality Due to Road Surface Irregularities: Comparison of Different Methods Applied on a Set of Real Road Profiles, Coatings. 7 (2017) https://doi.org/10.3390/coatings7050059.

7. D. Kim, K. Min, H. Kim, K. Huh, Vehicle sideslip angle estimation using deep ensemble-based adaptive Kalman filter, Mechanical Systems and Signal Processing. 144 (2020) 106862. https://doi.org/10.1016/j.ymssp.2020.106862.

8. C. Liu, J. Zhou, A. Gerhard, J. Kubenz, G. Prokop, Characterization of the Vehicle Roll Movement with the Dynamic Chassis Simulator, in: Vehicle and Automotive Engineering 2, Cham, 2018, pp. 129-41.

9. B. Gao, Q. Liang, Y. Xiang, L. Guo, H. Chen, Gear ratio optimization and shift control of 2-speed I-AMT in electric vehicle, Mechanical Systems and Signal Processing. 50-51 (2015) 615-31. https://doi.org/10.1016/j.ymssp.2014.05.045.

10. G. Li, D. Görges, Optimal control of the gear shifting process for shift smoothness in dual-clutch transmissions, Mechanical Systems and Signal Processing. 103 (2018) 23-38. https://doi.org/10.1016/j.ymssp.2017.09.040.

11. R. M. B. R. A. Shah, C. Cheng, R. P. Jones, J. Pawar, Modelling of 4WD vehicle driveability during tip-in/tip-out events, in: Proceedings of 22nd International Symposium on Dynamics of Vehicle on Road and Tracks, Manchester, United Kingdom, 2011, pp. 85.

12. R. E. Dorey, C. B. Holmes, Vehicle Driveability - Its Characterisation and Measurement, in: International Congress \& Exposition, Detroit, USA, 1999, pp. 8.

13. W. Wang, L. Cao, F. Qu, Driving Performance Test of Plug-in Hybrid Electric Vehicle Based on AVL-DRIVE, in: 2019 5th International Conference on Control, Automation and Robotics (ICCAR), Beijing, China, 2019, pp. 771-5.

14. S. Ciceo, Y. Mollet, M. Sarrazin, J. Gyselinck, H. V. d. Auweraer, C. Martiş, Model-based design and testing for electric vehicle driveability analysis, in: 2016 IEEE 16th International Conference on Environment and Electrical Engineering (EEEIC), Florence, Italy, 2016, pp. 1-4.

15. J. Pawar. Low frequency powertrain and vehicle system dynamics, University of Warwick, United Kingdom, 2009.

16. R. Hibino, T. Jimbo, H. Yamaguchi, Y. Tsurumi, H. Otsubo, S. Kato, Clarification of Transient Characteristics by Coupled Analysis of Powertrains and Vehicles, SAE Int J Passeng Cars - Mech Syst. 9 (2016) 216-26. https://doi.org/10.4271/2016-01-1314.

17. D. Wang, M. Jiang, K. He, X. Li, F. Li, Study on vibration suppression method of vehicle with engine start-stop and automatic start-stop, Mechanical Systems and Signal Processing. 142 (2020) 106783. https://doi.org/10.1016/j.ymssp.2020.106783.

18. R. M. B. R. A. Shah, R. P. Jones, J. Pawar, System modelling and analysis of the driveability response of 4 WD vehicle, International Review of Mechanical Engineering. 6 (2012) 595-601. 
19. M. Ehsani, Y. Gao, S. Longo, K. Ebrahimi, Modern electric, hybrid electric, and fuel cell vehicles. 3rd ed, Boca Raton, USA, CRC press, 2018.

20. D. Hao, C. Zhao, Y. Huang, A Reduced-Order Model for Active Suppression Control of Vehicle Longitudinal Low-Frequency Vibration, Shock and Vibration. 2018 (2018) 5731347. https://doi.org/10.1155/2018/5731347.

21. A. Scamarcio, P. Gruber, S. De Pinto, A. Sorniotti, Anti-jerk controllers for automotive applications: A review, Annual Reviews in Control. 50 (2020) 174-89. https://doi.org/10.1016/j.arcontrol.2020.04.013.

22. S. R. Johnson, J. W. Subhedar, COMPUTER OPTIMIZATION OF ENGINE MOUNTING SYSTEMS, in: 3rd International Conference on Vehicle Structural Mechanics Michigan, USA, 1979, pp. 8.

23. V. Ivanov, D. Savitski, B. Shyrokau, A Survey of Traction Control and Antilock Braking Systems of Full Electric Vehicles With Individually Controlled Electric Motors, IEEE Transactions on Vehicular Technology. 64 (2015) 3878-96. https://doi.org/10.1109/TVT.2014.2361860.

24. J.-L. Zhang, C. L. Yin, J. Zhang, Improvement of drivability and fuel economy with a hybrid antiskid braking system in hybrid electric vehicles, International journal of automotive technology. 11 (2010) 205-13. https://doi.org/10.1007/s12239-010-0026-0.

25. S. Oleksowicz, K. Burnham, N. Phillip, P. Barber, E. Curry, W. Grzegozek, Regenerative Braking Control for High Level Deceleration on Low Mu Surface, SAE Int J Alt Power. 4 (2015) 16. https://doi.org/10.4271/2015-01-9141.

26. M. V. van der Seijs, D. de Klerk, D. J. Rixen, General framework for transfer path analysis: History, theory and classification of techniques, Mechanical Systems and Signal Processing. 68-69 (2016) 217-44. https://doi.org/10.1016/j.ymssp.2015.08.004.

27. A. Acri, E. Nijman, A. Acri, G. Offner, Influences of system uncertainties on the numerical transfer path analysis of engine systems, Mechanical Systems and Signal Processing. 95 (2017) 106-21. https://doi.org/10.1016/j.ymssp.2017.03.037.

28. A. Diez-Ibarbia, M. Battarra, J. Palenzuela, G. Cervantes, S. Walsh, M. De-la-Cruz, et al., Comparison between transfer path analysis methods on an electric vehicle, Applied Acoustics. 118 (2017) 83-101. https://doi.org/10.1016/j.apacoust.2016.11.015.

29. Y. Zhang, X. Huang, Q. Zhao, Sensitivity analysis for vibration transfer path systems with non-viscous damping, Journal of Vibration and Control. 17 (2011) 1042-8. https://doi.org/10.1177/1077546309356235.

30. M. Haeussler, D. C. Kobus, D. J. Rixen, Parametric design optimization of e-compressor NVH using blocked forces and substructuring, Mechanical Systems and Signal Processing. 150 (2021) 107217. https://doi.org/10.1016/j.ymssp.2020.107217.

31. T. Jimbo, R. Hibino, H. Yamaguchi, H. Matsunaga, H. Otsubo, Multiway analysis of vehicle acceleration behavior, in: Proceedings of the ISMA, Leuven, Belgium, 2014, pp. 2014.

32. N. Zhang, T. Chen, M. Zheng, L. Luo, P. Liu, Real-time identification of vehicle body motion-modes based on motion-mode energy method, Mechanical Systems and Signal Processing. 143 (2020) 106843. https://doi.org/10.1016/j.ymssp.2020.106843.

33. R. M. B. R. A. Shah, C. Cheng, R. P. Jones, J. Pawar, Modelling of 4 WD vehicle driveability during tip-in/tip-out events, in: 22nd International Symposium on Dynamics of Vehicle on Road and Tracks, 2011, pp. 85.

34. H.-W. Yoon, J.-H. Bang, J.-H. Park, Development of Engine Mount System for Low Frequency Vibration Improvement, in: SAE World Congress \& Exhibition, Detroit, USA, 2008, pp. 10.

35. H. O. List, P. Schoeggl, Objective Evaluation of Vehicle Driveability, in: International Congress \& Exposition, Detroit, USA, 1998, pp. 9.

36. R. A. Krenz, Vehicle Response to Throttle Tip-In/Tip-Out, in: SAE Surface Vehicle Noise and Vibration Conference, Michigan, USA, 1985, pp. 793-800.

37. A. Pazooki, S. Rakheja, D. Cao, Modeling and validation of off-road vehicle ride dynamics, Mechanical Systems and Signal Processing. 28 (2012) 679-95. https://doi.org/10.1016/j.ymssp.2011.11.006. 